\title{
Purification of a Necrosis-Inducing, Host-Specific Protein Toxin from Spore Germination Fluid of Alternaria panax
}

\author{
H. A. Quayyum, M. Gijzen, and J. A. Traquair
}

Southern Crop Protection and Food Research Centre, Agriculture and Agri-Food Canada, London, ON N5V 4T3, Canada.

Current address of H. A. Quayyum: Pest Management Regulation Agency, Health Canada, Efficacy and Sustainability Assessment Division, 2720 Riverside Drive, Ottawa ON K1A 0K9, Canada. Accepted for publication 25 October 2002.

\begin{abstract}
Quayyum, H. A., Gijzen, M., and Traquair, J. A. 2003. Purification of a necrosis-inducing, host-specific protein toxin from spore germination fluid of Alternaria panax. Phytopathology 93:323-328.

Spore germination fluid of Alternaria panax, the causal agent of Alternaria blight of American ginseng (Panax quinquefolius), collected from water droplets or aqueous ginseng leaf extracts produced visible water-soaked lesions on wounded, detached leaflets after incubation for $48 \mathrm{~h}$. Maximum development of brown, necrotic spots occurred 4 to 5 days after inoculation on attached and detached ginseng leaflets. Of 15 plant species tested, only American ginseng was susceptible to applications of spore inoculum or spore germination fluid. The phytotoxic activity of the spore germination fluid was destroyed by heat and treatment with proteinase A. The phytotoxic factor was retained by an
\end{abstract}

ABSTRACT ultrafiltration membrane with a 30-kDa molecular mass cut-off. Purification of the phytotoxic protein, named AP-toxin, was performed by anion exchange and gel filtration chromatography. Bioactive fractions eluted as a single peak. By comparison with protein standards, a molecular mass of $35 \mathrm{kDa}$ was estimated for the native protein. The denatured protein toxin also had a mass of $35 \mathrm{kDa}$ as determined by sodium dodecyl sulfatepolyacrylamide gel electrophoresis analysis. Production of the protein toxin was induced on American ginseng leaflets and water extracts of ginseng leaves but not on leaves of other nonhost plants and their water extracts. The results show that $A$. panax produces a host-specific, proteinaceous toxin during colonization and pathogenesis of ginseng leaves.

Additional keywords: bioassay, chlorosis, conidia, disease, necrotroph, symptoms, virulence.
American ginseng (Panax quinquefolius L.) is highly valued in Asian countries as a traditional medicine and also for its uses in other food products. In artificial shade gardens, American ginseng is susceptible to a number of fungal pathogens of foliage and stems. Foliar disease incidence and severity are exacerbated by dense planting, long-term continuous cultivation for at least 4 years, poor air circulation and cool, humid growth conditions $(5,13,18)$.

Alternaria blight of leaves and stems of American ginseng is caused by the fungus Alternaria panax Whetzel. It is a very common disease of cultivated and wild ginseng. Infestations of $A$. panax result in yield losses of 10 to $20 \%$ of total crop (19). Stem infection of seedlings is initiated in the spring by overwintering conidia or mycelia in infested crop residues and mulches. The infection first appears in the field as elongated reddish to darkbrown lesions (18). The stem is girdled gradually and may collapse, causing damping-off of seedlings $(5,18,20)$. Foliar infections on older plants appear later in summer as rapidly enlarging circular, elliptical, or wedge-shaped, water-soaked necrotic spots that are light to dark brown. These spots often are surrounded by chlorotic margins.

Several other species or pathotypes of Alternaria cause leaf spot, leaf and stem blight, and damping-off symptoms on other plant species and many of them are reported to produce hostspecific and host-nonspecific toxins $(10,14,15,22)$. Eleven pathogen-host systems involving different species of Alternaria are reported to produce host-specific toxins $(14,15,25)$. Most of the host-specific toxins are low molecular weight secondary com-

Corresponding author: J. A. Traquair; E-mail address: traquairj@agr.gc.ca

Publication no. P-2003-0113-01R

For the Department of Agriculture and Agri-Food, Government of Canada (C) Minister of Public Works and Government Services Canada 2003. pounds with diverse chemical structures and are toxic only to the host plant and at very low concentration. A number of investigators have shown that host-specific toxins (HSTs) have a primary role in the pathogenesis of Alternaria diseases in plants $(8,14,25)$. These HSTs were reported to be produced both in culture filtrates and in the spore germination fluids (SGFs) of the pathogens. In many cases, host-specific, cyclic peptide and polyketide toxins were isolated and purified from 14- to 25-day-old culture filtrates of Alternaria spp. $(2,15,25)$. Direct evidence for the involvement of HSTs in pathogenesis by Alternaria spp. is reported in the studies of toxins from infected plants and SGFs collected from host plants after inoculation with A. carthami (26), A. brassicae (1), A. alternata tobacco pathotype (9), A. tenuissima (12), A. brassicae, and A. brassicicola (6).

Production of toxic compounds by a fungus in vitro does not always correlate with the development of symptoms on plants and the role of these compounds in pathogenesis is not always clear (23). In contrast, toxic metabolites released by germinating spores of pathogens during infection may play a direct and major role during the early stages of pathogenesis (11). Recently, Otani et al. (16) reported the production of an HST named AB-toxin in spore germination fluid produced by A. brassicicola, the causal agent of Alternaria leaf spot on Brassica spp. The molecular mass of this toxic protein was reported to be $35 \mathrm{kDa}$.

The objectives of this study were to (i) to detect toxin in SGF produced on ginseng leaflets, (ii) determine the sensitivity of ginseng and related plant species in the family Araliaceae to SGF, and (iii) determine the nature of the toxin and to purify it from SGF.

\section{MATERIALS AND METHODS}

Propagation of ginseng. Pregerminated seed of American ginseng that had been stratified for 8 months were sown (two seeds 
per pot) in plastic pots $(10.0$ by $8.5 \mathrm{~cm})$ containing $200 \mathrm{~g}$ of dry Pro-Mix 'BX' (Premier, Canada) mixed with black clay-loam soil (4:1). Plants were grown in a growth chamber at $18^{\circ} \mathrm{C}$ (day and night) with a 16-h light period and $70 \%$ relative humidity under two layers of Lumite shade fabrics (Plant Products Co., Brampton, Ontario, Canada) which reduced light intensity by approximately $70 \%$. The intensity of light was $78 \mu \mathrm{mol} \mathrm{s}^{-1} \mathrm{~m}^{-2}$ under the shade cloth. Seedlings were thinned to one plant per pot and fertilized biweekly with a solution of 20-20-20 (N-P-K) (Plant Product Co.) at $1 \mathrm{~g} \mathrm{liter}^{-1}$. The plants were watered on alternate days.

Isolation, inoculum production, and pathogenicity of $A$. panax. A. panax (isolate JAT 2120) was isolated from necrotic spots in naturally infected leaves of American ginseng grown in a research plot at the Agriculture and Agri-Food Canada (AAFC) Research Center at Delhi, Ontario and was maintained routinely on potato dextrose agar (PDA) at $5^{\circ} \mathrm{C}$. Stock cultures are maintained at the AAFC Research Center in London.

The isolate was grown on V8 juice agar in petri dishes which were kept in a growth cabinet for 14 days at $25^{\circ} \mathrm{C}$ (day and night) constant temperature with $14 \mathrm{~h}$ of light at approximately $23.0 \mu \mathrm{mol} \mathrm{s}{ }^{-1} \mathrm{~m}^{2}$ light intensity from cool fluorescent lights. The colonies were flooded with $10 \mathrm{ml}$ of sterile water and the spores were dislodged by gentle shaking. The resultant spore suspension was concentrated by centrifuging at $500 \times g$ for $5 \mathrm{~min}$, and the spore pellets were suspended in sterile distilled water and adjusted to the required concentration (number of spores $\mathrm{ml}^{-1}$ ) with the aid of a hemacytometer.

Pathogenicity tests were carried out on leaves of 1-month-old ginseng seedlings. The attached leaflets were surface sterilized with $70 \%$ ethanol and the upper surface of each leaflet was spot inoculated in the center with a $20-\mu \mathrm{l}$ droplet of spore suspension $\left(10^{5}\right.$ spores $\left.\mathrm{ml}^{-1}\right)$ with a sterile micropipette. Control leaflets received $20 \mu \mathrm{l}$ of sterile water. The plants were kept in separate plastic bags, tightly sealed, and placed in growth cabinets at $25^{\circ} \mathrm{C}$ (day and night), $70 \%$ relative humidity, and 14-h photoperiods at a light intensity of approximately $23.0 \mu \mathrm{mol} \mathrm{s} \mathrm{s}^{-1}$. The plastic bags were opened after $24 \mathrm{~h}$ of incubation and the infected plants were examined for symptoms after 5 days.

Host range. Leaves or leaflets of 1-month-old potted seedlings and the fully developed uppermost leaves or leaflets of mature plants, Hedera helix L. (English ivy), Polyscias fruticosa L. (Ming aralia), Schefflera actinophylla L. (umbrella tree), Fatsia japonica L. (Japanese aralia), Dizygotheca elegantissima L. (false aralia), Panax quinquefolius L. (American ginseng), Brassica napus L. (oil seed rape), Brassica oleracea L. (cabbage), Brassica oleracea L. var. botrytis L. (cauliflower), Glycine max L. (soybean), Phaseolus vulgaris L. (snap bean), Solanum tuberosum L. (potato), Lycopersicon esculentum Mill. (Tomato), Triticum aestivum L. (wheat), and Zea mays L. (maize), belonging to five families from subclasses Monocotyledonae and Dicotyledonae, were tested for their susceptibility to $A$. panax as described previously.

Production of SGFs. Ginseng leaves were collected from 1-month-old plants and surface sterilized by dipping into $70 \%$ ethanol for $30 \mathrm{~s}$. The detached leaflets were placed separately with lower surface upward on sterile glass microscope slides in petri dishes lined with sterile Whatman No. 1 filter paper. The filter paper was moistened with $1.5 \mathrm{ml}$ of sterile distilled water. A $40-\mu \mathrm{l}$ spore suspension ( 6 to 10 droplets, $10^{5}$ spores $\mathrm{ml}^{-1}$ ) was applied on the lower surface of leaflets. The petri dishes were sealed with parafilm and incubated in a controlled environment growth cabinet at $25^{\circ} \mathrm{C}$ with a 14 -h light period at a light intensity of $23.0 \mu \mathrm{mol} \mathrm{s} \mathrm{s}^{-1} \mathrm{~m}^{-2}$ provided by cool fluorescent light. Control leaflets received only $40-\mu \mathrm{l}$ droplets of sterile distilled water. After 48 and $72 \mathrm{~h}$ of incubation, droplets containing SGFs and the sterile water controls were collected in $1.5-\mathrm{ml}$ microfuge tubes by a micropipette and centrifuged at $1,000 \times g$ for $10 \mathrm{~min}$. The supernatants were collected and filtered through a syringe-driven filter unit, Millex-GV, (Millipore Corporation, Bedford, MA), with a $0.22-\mu \mathrm{m}$ low-protein-binding durapore membrane. The filter-sterilized supernatants were used immediately as SGF or stored at $4^{\circ} \mathrm{C}$ for further use.

Bioassay with SGF. Ginseng leaflets were collected from 1-month-old plants and surface sterilized by dipping into $70 \%$ ethanol for $30 \mathrm{~s}$. The detached leaflets were air dried under hood to remove ethanol from surfaces. The leaflets with lower surface facing upward were placed separately on a sterile glass slides in petri dishes lined with a moistened filter paper.

An area of approximately $0.5 \mathrm{~mm}^{2}$ on the lower surface of each leaflet was scratched gently with the sterile pipette tip and a $40-\mu 1$ droplet of SGF (collected after $48 \mathrm{~h}$ of incubation on leaflets) was applied at the wounded sites to determine the phytotoxicity of SGF. When droplets of SGF rapidly drained through the leaflets onto the slides, these leaflets were discarded. One set of leaflets was treated with SGF without wounding. Control leaflets were treated with sterile distilled water. The petri dishes were sealed with parafilm and incubated in a growth cabinet at $24^{\circ} \mathrm{C}$ with a 14-h light period provided by cool fluorescent lights. Initial symptoms were observed at 24 to $48 \mathrm{~h}$ after treatment of leaflets. Leaves were examined daily. Five days after incubation, the maximum length and width of lesions around the treated sites were measured. The extent of leaf damage (lesion area) was calculated as maximum lesion length times maximum lesion width.

Effect of SGF on plant species other than ginseng. To test the response of nonhosts of $A$. panax to the SGF, the same set of plant species were used as was described for the host range test. Leaves or leaflets were collected from 1-month-old plants and were treated with SGF as described previously. Five days after treatment, the maximum length and width of any lesions which developed around the treated sites were measured.

Effect of proteinase $A$ and heat treatments on toxin activity of SGF. The SGF $(0.5 \mathrm{ml})$ was mixed with $0.5 \mathrm{ml}$ of proteinase A (Sigma-Aldrich, Oakville, ON) at the concentration of 5.0, 10.0, and $15 \mu \mathrm{g} \mathrm{ml}^{-1}$ and were incubated at $35^{\circ} \mathrm{C}$ in a water bath for $1 \mathrm{~h}$. Proteinase $\mathrm{A}$ alone and SGF incubated at the same conditions served as control.

The SGF $(0.5 \mathrm{ml})$ in Eppendorf tubes was heated in a water bath at $30,45,60,80$, and $100^{\circ} \mathrm{C}$ for $15 \mathrm{~min}$. Samples of SGF also were incubated at room temperature $\left(22^{\circ} \mathrm{C}\right)$ and at $4^{\circ} \mathrm{C}$. An aliquot $(0.5 \mathrm{ml})$ of concentrated SGF of $A$. panax produced in presence of ginseng leaf extracts $\left(50 \mathrm{~g} \mathrm{liter}^{-1}\right)$ was boiled for $15 \mathrm{~min}$. The effect of Proteinase A and heat treatments on the phytotoxicity of SGFs was evaluated in triplicate using ginseng detached-leaflet bioassay.

Production of SGF on leaves of different plant species. Detached leaves of Hedera helix L. (English ivy), Fatsia japonica L. (Japanese aralia), Dizygotheca elegantissima L. (false aralia), Schefferella actiniphylla L. (umbrella tree), Brassica oleracea L. (cabbage), Lycopersicon esculentum Mill. (tomato), Capsicum annum L. (pepper.), Zea mays L. (maize), Phaseolus vulgaris L. (snap bean), and Panax quinquefolius L. (American ginseng) were surface sterilized by wiping with $70 \%$ ethanol. The leaves were placed with lower surface upward on sterile microscope glass slides in disposable sterile petri dishes lined with sterile moistened filter papers (Whatman no. 1). The surface of leaves was inoculated with $40-\mu \mathrm{l}$ droplets of spore suspension, 8 to 10 droplets per leaf, of A. panax (JAT 2120) and the SGFs were collected after $48 \mathrm{~h}$ of incubation at $25^{\circ} \mathrm{C}$. The SGF was concentrated by filtration using a centricon centrifugal filter device with ultra filtration membranes of 10 and $30 \mathrm{kDa}$ cut-off limits (Millipore Corporation). The phytotoxicity of both concentrated and unconcentrated SGF was determined using ginseng detached-leaflet bioassay.

The leaflets were cut into small pieces $(5 \times 5 \mathrm{~mm})$ from inoculated sites and cleared in $0.15 \%$ (wt/vol) trichloroacetic acid in chloroform and methanol (3:1) solution until chlorophyll was completely removed. The leaflet pieces were stained with $0.01 \%$ 
cotton blue in lactophenol and were examined for conidial germination with a bright field light microscope.

Production of SGF of $A$. panax with leaf extracts of different plant species. The leaf extracts of American ginseng, umbrella tree, and cabbage were prepared by autoclaving freshly harvested leaves in distilled water for $20 \mathrm{~min}$, at the rate of $1,10,50$, and $100 \mathrm{~g}$ of leaves per liter of water. Fourteen-day-old cultures of $A$. panax grown on V8-juice agar were flooded with $10 \mathrm{ml}$ of distilled water and the spores were dislodged by gentle shaking. The resultant spore suspension was centrifuged at $500 \times g$ for $5 \mathrm{~min}$ and the pellets were resuspended in leaf extracts of different plant species to obtain the final concentration of $10^{5}$ spores $\mathrm{ml}^{-1}$. Control treatment for spore suspension was prepared with sterile distilled water. Droplets of spore suspension $(40 \mu \mathrm{l})$ were placed within sterile petri dishes with 30 to 40 droplets per dish. The petri dishes were sealed with parafilm and incubated for $48 \mathrm{~h}$ in a growth cabinet at $25^{\circ} \mathrm{C}$ with a 14-h light period. The spore germination fluids from spore droplets were collected, filter sterilized, and concentrated. The phytotoxicity of concentrated and unconcentrated SGFs was determined using ginseng detached-leaflet bioassay.

Purification of protein toxin from SGF. Total protein content of SGF of A. panax and sterile water droplets collected from control leaflets were determined using the method described by Bradford (4) with bovine serum albumin (Sigma-Aldrich) as a standard.

The collected SGFs were concentrated by centrifugation using a $30-\mathrm{kDa}$ centricon filter device as described previously. Toxin activities of the concentrated samples (retentates), filtrates, and unconcentrated SGFs were determined using detached ginseng leaflet bioassay as described previously. The total protein content of concentrated samples and unconcentrated SGFs was measured using Bradford assay (4).

Ion-exchange chromatography (DE-52 cellulose, Whatman) was carried out to determine whether the toxin protein binds to anion exchanger. Concentrated SGF (1 ml) (10x) was loaded onto the column $(10.0$ by $0.5 \mathrm{~cm})$ and the flow through was collected. The column then was washed with $2.0 \mathrm{ml}$ of wash buffer $(20 \mathrm{mM}$ Tris $\mathrm{Cl}, \mathrm{pH} 8.0$ ) and the wash collected. The anionic protein fraction bound to the column was step eluted with $2.0 \mathrm{ml}$ each of 150, 250, and $500 \mathrm{mM} \mathrm{NaCl}$ in $20 \mathrm{mM}$ Tris $\mathrm{Cl}$ buffer, $\mathrm{pH} 8.0$, and the eluents were collected.

All the samples obtained from DE-52 column were dialyzed against $10 \mathrm{mM}$ Tris $\mathrm{Cl}, \mathrm{pH} 8.0$, overnight at $4{ }^{\circ} \mathrm{C}$ using dialysis tubing with a 6,000 to 8,000 molecular weight cut-off limit (Spectra/Por; Spectrum Medical Industries, Inc., Houston, TX). The phytotoxicity of the desalted fractions were determined by ginseng detached-leaflet bioassay as described previously.

In subsequent purifications, the anion exchange resin was added directly to the SGF $\left(0.1 \mathrm{~g} \mathrm{ml}^{-1}\right)$ and mixed well with a vortex mixture. The mixture then was centrifuged at $10,000 \times g$ for 5 min and the supernatant was collected. The supernatant was filter sterilized and its phytotoxicity was determined by ginseng detachedleaflets bioassay. The total protein content of the DE-52 purified SGF was determined by the method of Bradford (4) and onedimensional sodium dodecyl sulfate-polyacrylamide gel electrophoresis was carried out using the modified system of Laemmli, as described by Fling and Gregerson (7).

Further fractionation and purification of toxin protein in SGF was carried out by gel filtration chromatography (Superdex-75) using a fast protein liquid chromatography (FPLC) apparatus (Pharmacia Biotech, Uppsala, Sweden). Two milliliters of concentrated (10X) DE-52 purified SGF was loaded onto the column $(1.6 \times 60 \mathrm{~cm})$. Elution was carried out with $50 \mathrm{mM} \mathrm{NaCl}$ in $20 \mathrm{mM}$ Tris $\mathrm{Cl}$ buffer, $\mathrm{pH} 8.0$; the flow rate was $0.5 \mathrm{ml} \mathrm{min}^{-1}$ and absorbance (A) was monitored at $280 \mathrm{~nm}$. Forty fractions of $1.8 \mathrm{ml}$ each were collected after elution of column void volume. Phytotoxicity of the fractions were determined using ginseng detached-leaflet bioassay as described previously. The total protein content of each fraction was measured by Bradford assay (4). The protein profiles of bioactive fractions were monitored by SDS-PAGE and the protein bands in gel were visualized by silver staining (3).

Data analysis. Data from different experiments were analyzed by one-way analysis of variance (ANOVA) using Minitab statistical software (release 11; Minitab Inc., State College, PA). Significant differences between means were determined by the honestly significant difference (HSD)-Tukey's test.

\section{RESULTS}

Pathogenicity and host range of $A$. panax on intact plants. Isolate JAT 2120 produced necrotic disease symptoms on American ginseng leaflets of intact plants. The lesions, $166.0 \pm$ $34.0 \mathrm{~mm}^{2}$ in size at 5 days after inoculation, developed initially as rapidly enlarging almost circular gray to dark brown necrotic spots surrounded by yellowish margins (data not shown). Plant species from the families Cruciferae, Leguminosae, Solanaceae, and Graminae and even other representatives of the ginseng family (Araliaceae) had no visible lesions on leaves after inoculation with $A$. panax.

Phytotoxic effect of SGF on detached leaflets. The SGF collected from droplets of an aqueous spore suspension of $A$. panax (JAT 2120) incubated for 48 to $72 \mathrm{~h}$ on American ginseng leaflets was phytotoxic using detached-leaflet bioassays. No symptoms were observed on leaflets in the absence of wounding or wounded leaflets treated with sterile water. The development of SGF-induced, water-soaked chlorotic lesions was followed by the development of brownish necrotic spots on ginseng leaflets (Fig. 1). The SGFs collected after 48 and $72 \mathrm{~h}$ produced lesions of similar size, $236.0 \pm 26.5 \mathrm{~mm}^{2}$ and $292.0 \pm 17.5 \mathrm{~mm}^{2}$, respectively. Approximately $62 \pm 2.5$ and $73 \pm 1.9 \%$ of conidia had germinated on ginseng leaflets after 48 and $72 \mathrm{~h}$ of incubation, respectively. In another experiment, SGF collected after $48 \mathrm{~h}$ was concentrated 10 -fold by microconcentrators with 10 and $30 \mathrm{kDa}$ molecular mass cut-off ultramembranes. The retentates (concentrated SGF) from 10 - and $30-\mathrm{kDa}$ microconcentrators produced significantly $(P<0.001)$ larger lesions $\left(227.0 \pm 15.6\right.$ and $241.0 \pm 15.9 \mathrm{~mm}^{2}$, respectively) on ginseng leaflets than those produced by the same unconcentrated SGF $\left(29.0 \pm 5.5 \mathrm{~mm}^{2}\right)$ for this experiment. The two microconcentrator filtrates did not produce any visible lesions in ginseng leaflets.
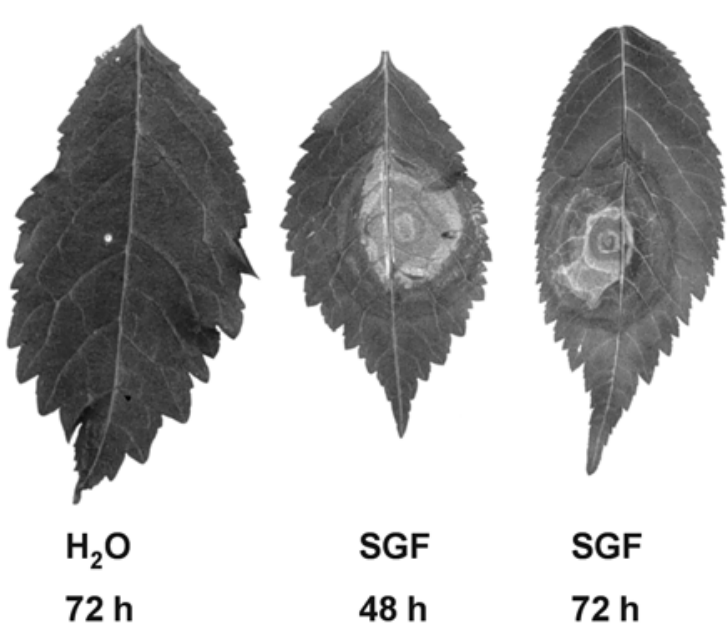

Fig. 1. Water-soaked chlorotic lesions developed in leaflets of American ginseng at 5 days after treatment with spore germination fluid of Alternaria panax (JAT 2120) collected after 48 and $72 \mathrm{~h}$ of incubation on leaflets of American ginseng. Control leaflet was treated for same time with fluid of sterile distilled water after incubation of $72 \mathrm{~h}$ on leaflets of American ginseng. 
Total protein content of SGF. A 10 -fold concentration of SGF with 10 - and $30-\mathrm{kDa}$ cut off ultramembranes increased total protein content, 1,876.0 and 2,069.0 $\mu \mathrm{g} \mathrm{ml}^{-1}$, respectively, and retentates were significantly different in total protein content of unconcentrated SGF, $405.0 \mu \mathrm{g} / \mathrm{ml}(P<0.001)$. A small amount of protein was present in filtrates obtained from both microconcentrators. There was a strong positive correlation $\left(R^{2}=0.99\right)$ between protein content of SGFs and the lesion area developed after treatment with SGFs in ginseng leaflets (data not shown).

Heat and proteinase A treatment on toxin activity of SGF. The toxin activity of SGF after heating at 22,30 , and $37^{\circ} \mathrm{C}$ for 15 min was similar to the toxin activity of SGF stored at $4^{\circ} \mathrm{C}$. However, the toxin activity of SGF was reduced drastically when the sample was heated at $45^{\circ} \mathrm{C}$ for $15 \mathrm{~min}$. A trace of toxin activity of SGF in ginseng leaflets was detected after heating at $60^{\circ} \mathrm{C}$ for $15 \mathrm{~min}$, and the activity was completely destroyed after heating at 80 and $100^{\circ} \mathrm{C}$ (Fig. 2).

The toxin activity of SGF was also lost after treatment with 4, 8, and $12 \mu \mathrm{g}$ of proteinase A per $\mathrm{ml}$ of SGF at $35^{\circ} \mathrm{C}$ for $1 \mathrm{~h}$ (Table 1 ).

Phytotoxicity of SGF on plant species other than American ginseng. The treatment of leaves or leaflets of the same plant species that were used in host range studies of A. panax with SGF produced a water-soaked necrotic lesion, $55.7 \pm 9.9 \mathrm{~mm}^{2}$, only on ginseng leaflets. SGF was not phytotoxic to leaves or leaflets of Brassicoid, Solanaeceous, Gramminoid, or Leguminous plant species and had no visible effect on leaves of Araliaceous plant species other than American ginseng.

Phytotoxicity of SGF collected from different plant species. SGF of A. panax collected from inoculated leaves showed that toxic SGF was found only on American ginseng. SGF collected

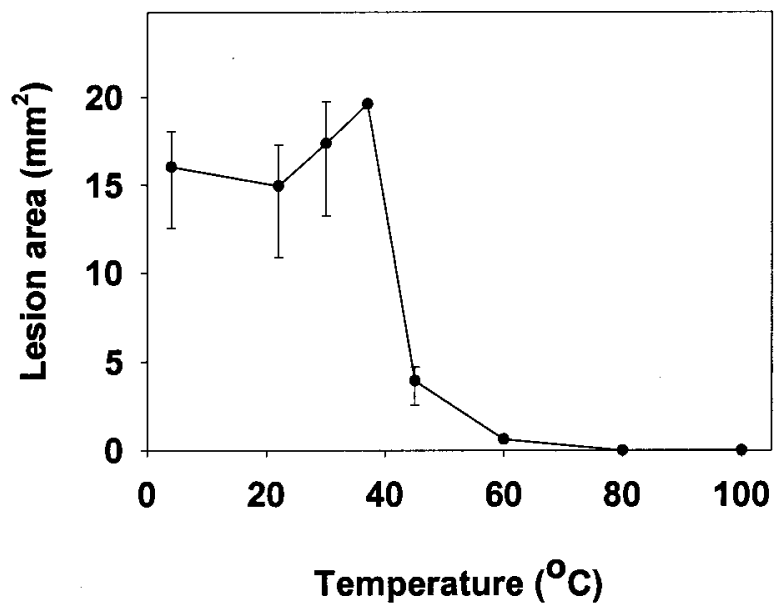

Fig. 2. Effect of heating for $15 \mathrm{~min}$ at different temperatures on the phytotoxic activity of spore germination fluid of Alternaria panax (JAT 2120) in ginseng leaflets. Vertical bars represent standard error of the mean.

TABLE 1. Effects of proteinase A treatment on lesion development by spore germination fluid of Alternaria panax in American ginseng leaflets ${ }^{\mathrm{a}}$

\begin{tabular}{lc}
\hline Treatment & Lesion area $\left(\mathrm{mm}^{2}\right)$ \\
\hline Proteinase A $(4 \mathrm{mg} / \mathrm{ml})+$ spore germination fluid & $0.8 \pm 0.0$ \\
Proteinase A (4 mg/ml) alone & $0.0 \pm 0.0$ \\
Proteinase A (8 mg/ml) + spore germination fluid & $0.8 \pm 0.0$ \\
Proteinase A $(8 \mathrm{mg} / \mathrm{ml})$ alone & $0.0 \pm 0.0$ \\
Proteinase A (12 mg/ml) + spore germination fluid & $0.8 \pm 0.0$ \\
Proteinase A (12 mg/ml) alone & $0.0 \pm 0.0$ \\
Spore germination fluid + buffer & $21.2 \pm 2.5$ \\
Spore germination fluid alone & $22.2 \pm 4.8$ \\
\hline
\end{tabular}

${ }^{\text {a }}$ Mean \pm SE. Lesion area was calculated and recorded as maximum length by maximum width after inoculation of each $0.5-\mathrm{mm}^{2}$ scratch wound on detached ginseng leaflets with $40-\mu 1$ droplets of test solution and incubation of leaflets in separate moist chambers for 5 days. from nine other plant species classified in the families Araliaceae, Cruciferae, Solanaceae, Leguminosae, or Gramineae after inoculating with the same spore suspensions did not produce lesions $\left(0.5 \mathrm{~mm}^{2}\right)$ that were significantly different $(P<0.001)$ from wounded controls treated with water. Lesions produced by SGF from American ginseng $\left(28.0 \pm 2.0 \mathrm{~mm}^{2}\right)$ were significantly different $(P<0.001)$ from wounded controls and the other test plants.

The spores of $A$. panax germinated on inoculated leaves of different plant species (Fig. 3). However, the percent germination varied with plant species; the greatest germination of conidia $(92 \pm 1.9 \%)$ was observed on the leaves of $S$. actinophylla (Araliaceae) and the least germination (46 $\pm 1.7 \%)$ was observed on D. elegantissima (Araliaceae). The toxin activity of SGF of $A$. panax collected from different plant species is not correlated with the germination of spores.

Phytotoxicity of SGF produced with leaf extracts of different plant species. SGF obtained with 50- and 100-g ginseng leaf extracts produced significantly greater $(P<0.001)$ lesion areas than the same treatments with the other two species, $B$. oleracea and $S$. actinophylla. Unconcentrated SGF produced with leaf extracts of S. actinophylla and B. oleracea (cabbage) did not produce lesions in ginseng leaflets. However, cabbage leaf extracts at higher concentration (100 g of leaves per liter of water) were slightly toxic $\left(2.6 \pm 0.2 \mathrm{~mm}^{2}\right)$ to ginseng leaflets.

The germination of $A$. panax spores varied when incubated with leaf extracts of different plant species (Fig. 4). The spore germination varied from $23 \%$ in extracts of $B$. oleracea leaves $(1 \mathrm{~g}$ of leaves per liter of distilled water) to $92 \%$ in S. actinophylla leaf extract (100 g of leaves per liter of distilled water). The germination of spores in the control (in sterile water) was only $2.3 \%$.

The phytotoxic activity of concentrated SGF produced with ginseng leaf extracts (50 $\mathrm{g}$ of leaves per liter of distilled water) was completely destroyed by heating the sample at 95 to $100^{\circ} \mathrm{C}$ for $15 \mathrm{~min}$.

Purification of protein toxin from SGF. The results of the ginseng detached-leaf bioassay with different fractions purified by anion exchange chromatography indicated that only unbound fractions (flow-through and wash-buffer) had toxin activity. The

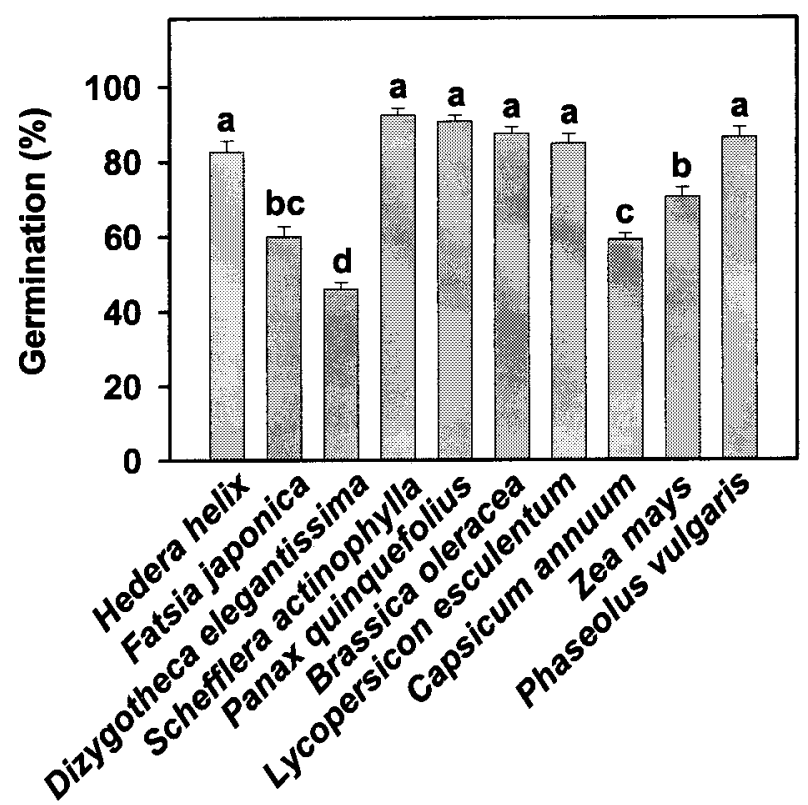

Plant species

Fig. 3. Germination of spores of Alternaria panax (JAT 2120) on leaves of different plant species. Mean $\pm \mathrm{SE}, n=4$. Bars surmounted by different letters are significantly different $(P<0.001)$ according to the honestly significant difference-Tukey's test. 
flow-through and wash-buffer fractions produced lesions of 15.0 and $35.0 \mathrm{~mm}^{2}$, whereas no lesions were produced by the bound fractions. Thus, treatment of the SGF with the anion exchange resin was an effective purification step because it removed many contaminating proteins without affecting the toxic activity of the extract. The anion exchange resin also clarified the SGF by adsorption of pigments, phenolics, or other darkly colored substances present in the raw extract. The DE-52-treated SGF was further purified by gel filtration chromatography. The toxic activity of all the fractions collected from gel filtration chromatography was determined using the ginseng detached-leaflet bioassay. Toxic activity eluted as a discrete peak in fractions 10 to 15 , with the greatest activity present in fraction 13. A representative separation is shown in Figure 5A. Bioactive fractions were plotted on the standard curve and the mass of the native protein in SGF was estimated to be $35 \mathrm{kDa}$ by comparing the elution volume of the most bioactive fractions with elution of protein standards. Protein profiles of these bioactive fractions and samples from other stages of the purification were determined by SDS-PAGE (Fig. 5B). This analysis showed that a protein band of $35 \mathrm{kDa}$ co-eluted with toxic activity. This $35-\mathrm{kDa}$ protein was the major protein band present in fraction 13 from the gel filtration purification. A summary of the purification steps, the protein content at each purification step, and the specific activity at each step is shown in Table 2 . The specific activity of the protein toxin from SGF was purified 842 -fold by the two-step procedure of anion exchange and gel filtration chromatography.

\section{DISCUSSION}

We observed that the spore suspension of A. panax and the SGF collected from ginseng produced similar lesions only in ginseng leaflets; therefore, we conclude that an HST (AP-toxin) is produced by A. panax in SGF. Furthermore, a chemical host factor or factors appeared to be involved in the production of AP-toxin in SGF, based on the observation that the AP-toxin was produced by A. panax on leaflets of American ginseng but not on nonhost plants or sterile distilled water. Similarly, water extracts from ginseng leaves but not from other plant species induced AP-toxin production. This toxin was retained by an ultrafiltration membrane with a $30-\mathrm{kDa}$ molecular mass cut-off and its activity was destroyed by heating. The chemical environment on the surfaces of ginseng leaflets on which the spores of $A$. panax germinate are thought to be important in the induction of phytotoxin. Our results

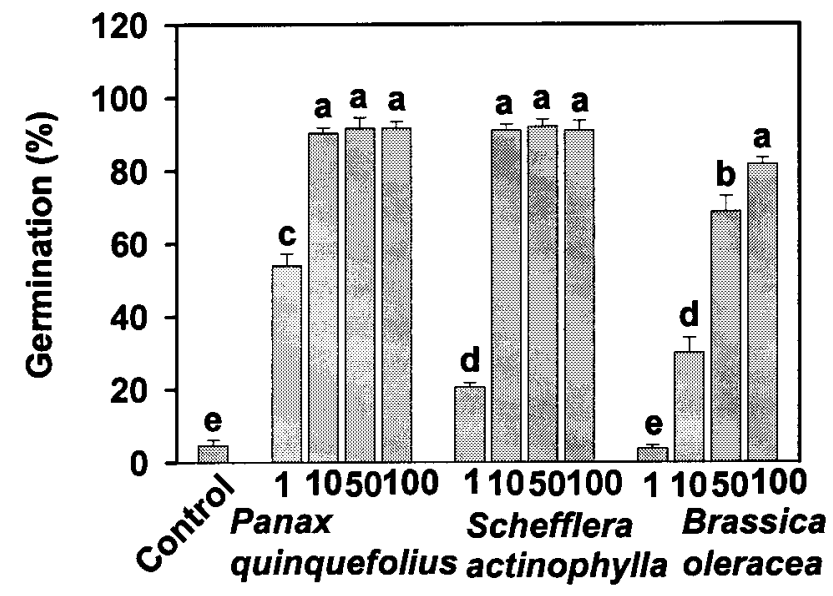

\section{Leaf extracts (g leaves/L water)}

Fig. 4. Germination spores of Alternaria panax (JAT 2120) in leaf extracts of different plant species. Mean \pm SE, $n=3$. Bars surmounted by different letters are significantly different $(P<0.001)$ according to the honestly significant difference-Tukey's test. are similar to those of Cooke et al. (6), who showed that the spores of $A$. brassicae and A. brassicicola failed to produce toxic SGF when germinated in sterile distilled water on the inner surface of plastic petri dishes. Robeson and Strobel (21) also demonstrated that $A$. helianthi produced a toxin, Deoxyradicin, in the liquid culture when it was supplemented with aqueous extract of the host plant. Our failure to detect the AP-toxin in culture filtrates of $A$. panax by bioassays (data not shown) and our observation of induction of AP-toxin production by $A$. panax on American ginseng leaves are consistent with the report by Otani et al. (17) that $\mathrm{AB}$-toxin is not present in culture filtrates of A. brassicicola. They reported that AB-toxin was detected in SGFs on host leaves but not on nonhost leaves or plastic plates and they suggested that AB-toxin production was induced by host-related factors during early stages of the host-pathogen interaction (17).

The toxic factor in the SGF collected after inoculation of $A$. panax on ginseng leaflets was retained by an ultrafiltration membrane with a 10 - and $30-\mathrm{kDa}$ molecular mass cut-off, indicating that the mass of the toxin is equal to or more than $30 \mathrm{kDa}$. The toxin activity of SGF was completely destroyed by heating to $100^{\circ} \mathrm{C}$ and by proteinase A treatment, suggesting that the toxin in

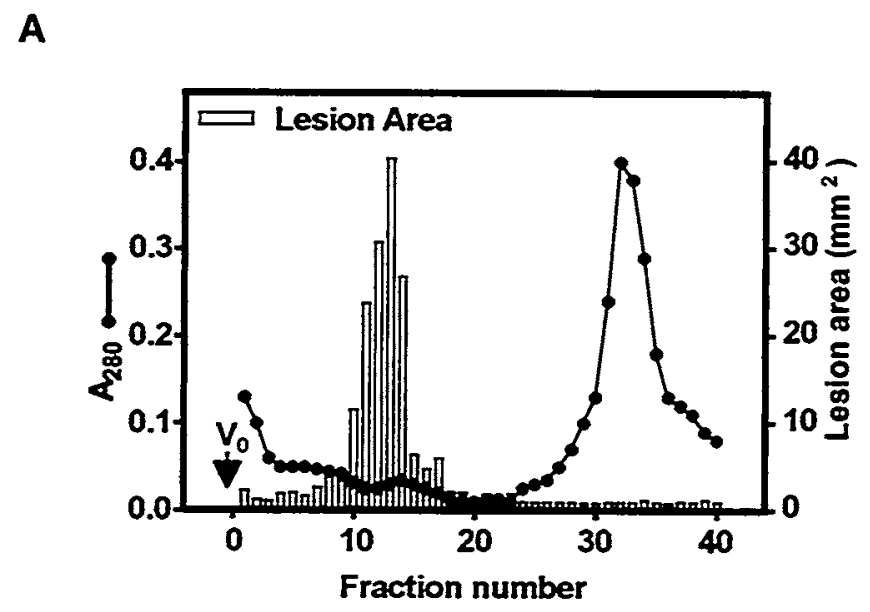

B

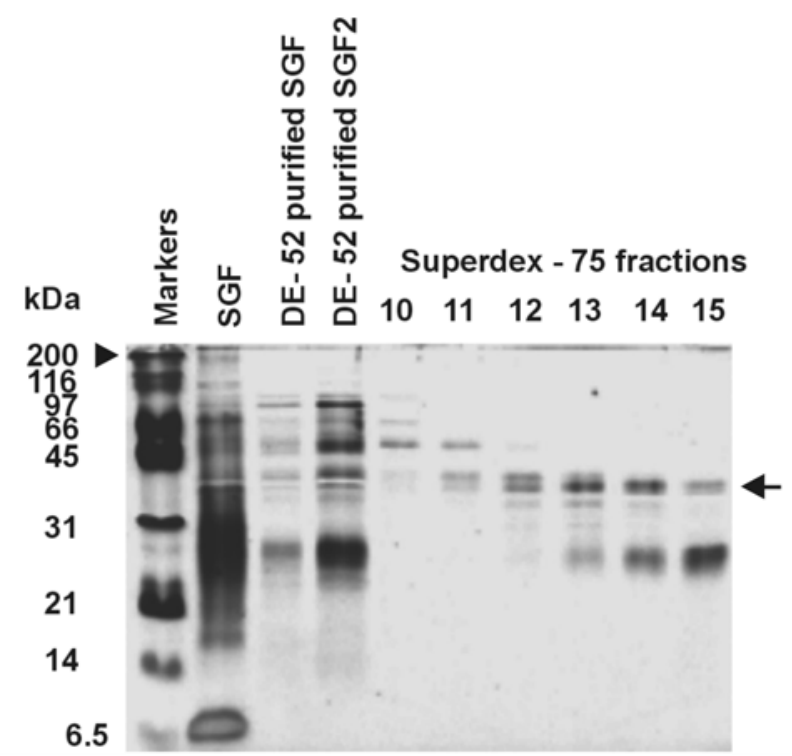

Fig. 5. Isolation and characterization of AP-toxin. A, Purification of lesion inducing toxin from DE-52-purified spore germination fluid of Alternaria panax (JAT 2120) by gel filtration chromatography (Superdex-75, Fast Protein Liquid Chromatography) (Vo = column void volume). B, Sodium dodecyl sulfate-gel electrophoresis analysis of proteins in bioactive fractions (fraction number 10 to 15 ) obtained from gel filtration chromatography (SGF $=$ spore germination fluid). DE-52-purified SGF2 is concentrated fluid. 
TABLE 2. Purification of a protein toxin from spore germination fluid of Alternaria panax

\begin{tabular}{lcccccc}
\hline Purification step & Volume $(\mathrm{ml})$ & Total protein $(\mathrm{mg})$ & Total activity $\left(\mathrm{mm}^{2}\right)^{\mathrm{a}}$ & Recovery $(\%)$ & Specific activity $\left(\mathrm{mm}^{2}\right) \mathrm{mg}^{-1 \mathrm{~b}}$ & Fold purification \\
\hline Crude & 25 & 12.1 & 13,938 & 100 & 1,152 \\
DE 52 & 20 & 1.66 & 8,000 & 57.4 & 1 \\
Superdex 75 & 1.8 & 0.026 & 1,814 & 13 & 4,819 & 5.2 \\
\hline
\end{tabular}

$\bar{a}$ Total activity (square millimeters) was calculated as the sum of lesion areas (maximum length by maximum width) for four replicate leaflets after incubation for 5 days.

${ }^{\mathrm{b}}$ Specific activity was calculated as total lesion area (square millimeters) per milligram of total protein.

SGF was proteinaceous. Moreover, a high positive correlation existed between total protein content in the SGF and the lesion sizes produced on American ginseng leaflets after treatment with the SGF. Variation in toxic bioactivity for unconcentrated SGF between experiments is attributed to difficulties in maintaining virulence of isolates in culture on artificial media. The pathogen had to be re-isolated repeatedly from host plants. The protein toxin was purified by DE-52 cellulose chromatography and by gel filtration. In comparison to standard proteins, its native and denatured molecular mass was estimated to be $35 \mathrm{kDa}$, indicating that the toxin is a monomer. Most of the HSTs produced by Alternaria spp. are low molecular weight secondary metabolites such as cyclic peptides and polyketides $(2,27)$. Only A. brassicicola, a pathogen of Brassica spp., was reported to produce a protein HST in germination fluid (16). Unlike A. panax, A. brassicicola is a small-spored Alternaria sp. (24). Although both $A$. panax and $A$. brassicicola produced $35-\mathrm{kDa}$ HSTs in their SGFs, A. brassicicola did not induce any disease symptoms on American ginseng (data not shown) and the protein toxin of A. panax SGF did not affect Brassica plants. Therefore, we assume that the HST produced by A. panax in SGF is different from HST produced by A. brassicicola. Further characterization and sequence analysis of each of these $35-\mathrm{kDa}$ protein toxins is required to assess their similarities to one another and to other known proteins.

\section{ACKNOWLEDGMENTS}

The work was partially supported by an operating grant to J. A. Traquair from the National Science and Engineering Research Council of Canada. We thank R. Reeleder for ginseng material.

\section{LITERATURE CITED}

1. Bains, P. S., and Tewari, J. P. 1987. Purification, chemical characterization and host-specificity of the toxin produced by Alternaria brassicae. Physiol. Mol. Plant Pathol. 30:259-271.

2. Ballio, A. 1991. Non-host-selective fungal phytotoxins: Biochemical aspects of their mode of action. Experientia 47:783-790.

3. Blum, H., Beier, H., and Gross, H. J. 1987. Improved staining of plant proteins, RNA and DNA in polyacrylamide gels. Electrophoresis 8:93-99.

4. Bradford, M. M. 1976. A rapid and sensitive method for the quantitation of microgram quantities of protein utilizing the principle of protein-dye binding. Anal. Biochem. 72:248-254.

5. Brammall, R. 1994. Fungal diseases: Ginseng, Alternaria blight. Pages 294-295 in: Diseases and Pests of Vegetable Crops in Canada. R. J. Howard, J. A. Garland, and W. L. Seaman, eds. Phytopathol. Soc. Entomol. Soc. of Canada, Ottawa.

6. Cook, D. E. L., Jenkins, P. D., and Lewis, D. M. 1997. Production of phytotoxic spore germination liquids by Alternaria brassicae and A. brassicicola and their effect on species of the family Brassicaceae. Ann. Appl. Biol. 131:413-426.

7. Fling, S. P., and Gregson, D. S. 1986. Peptide and protein molecular weight determination by electrophoresis using a high-molarity Tris buffer system without urea. Anal. Biochem. 155:83-88.

8. Knoche, H. W., and Duvick, J. P. 1987. The role of fungal toxins in plant disease. Pages 158-192 in: Fungal Infection of Plants. G. F. Pegg and P. G. Ayres, eds. Cambridge University Press, Cambridge.
9. Kodama, M., Suzuki, T., Otani, H., Kohmoto, K., and Nishimura, S. 1990. Purification and bioassay of host-selective AT-toxin from Alternaria alternata causing brown spot of tobacco. Ann. Phytopathol. Soc. Jpn. 56:628-636.

10. Nicola, M., and Visconti, A. 1992. Alternaria metabolites-chemical and biological data. Pages 449-557 in: Alternaria: Biology, Plant Diseases and Metabolites. J. Chelkowski and A. Visconti, eds. Elsevier Science Publishers, Amsterdam, The Netherlands.

11. Nishimura, S., and Kohmoto, K. 1983. Roles of toxins in pathogenesis. Pages 137-157 in: Toxin and Plant Pathogenesis. J. M. Daly and B. J. Deverall, eds. Academic Press, New York.

12. Nutsugah, S. K., Kohmoto, K., Otani, H., Kodama, M., and Sunkeswari, R. R. 1994. Production of a host-specific toxin by germinating spores of Alternaria tenuissima causing leaf spot of pigeon pea. J. Phytopathol. 140:19-30

13. Oliver, A., van Dalfsen, B., Van Lierop, B., and Buonassisi, A. 1992. American Ginseng Culture in the Arid Climates of British Columbia. Province of British Columbia, Ministry of Agriculture, Fisheries and Food.

14. Otani, H., Kodama, M., and Kohmoto, K. 1996. Physiological and molecular aspects of Alternaria host-specific toxin and plant interactions. Pages 258-267 in: Molecular Aspects of Pathogenicity and Resistance: Requirement for Signal Transduction. D. Mills, H. Kunoh, N. T. Keen, and S. Mayama, eds. The American Phytopathological Society, St. Paul, MN.

15. Otani, H., Kohmoto, K., and Kodama, M. 1995. Alternaria toxins and their effects on host plants. Can. J. Bot. 73(Suppl. 1):S453-S458.

16. Otani, H., Kohnobe, A., Kodama, M., and Kohmoto, K. 1998. Production of a host-specific toxin by germinating spores of Alternaria brassicicola. Physiol. Mol. Plant Pathol. 52:285-295.

17. Otani, H., Kohnobe, A., Kodama, M., and Kohmoto, K. 1998. Involvement of host factors in the production of host-specific toxin produced by Alternaria brassicicola. Pages 63-69 in: Molecular Genetics of HostSpecific Toxins in Plant Disease. K. Kohmoto and O. C. Yoder, eds. Kluwer Academic Publishers, Dordrecht, The Netherlands.

18. Parke, J. L., and Shotwell, K. M. 1989. Diseases of Cultivated Ginseng. Univ. Wisconsin Madison Coll. Agric. Life Sci. Res. Div. Res Bull. A3465.

19. Proctor, J. T. A., and Baily, W. G. 1987. Ginseng: Industry, botany and culture. Hortic. Rev. 9:187-236.

20. Reeleder, R. D., and Fisher, P. 1995. Diseases of Ginseng. Ontario Min. Agric. Food Rural Affairs Factsheet 95-003.

21. Robeson, D. J., and Strobel, G. A. 1986. The influence of plant extracts on phytotoxin production and growth rate of Alternaria helianthi. J. Phytopathol. 117:265-269.

22. Rotem, J. 1994. The genus Alternaria: Biology, Epidemiology and Pathogenicity. The American Phytopathological Society, St. Paul, MN.

23. Rudolph, K. 1976. Non-specific toxins. Pages 270-315 in: Physiological Plant Pathology. R. Heitefuss and P. H. Williams, eds. Springer-Verlag, New York

24. Simmons, G. E. 1992. Alternaria taxonomy: Current status, viewpoint, challenge. Pages 1-35 in: Alternaria: Biology, Plant Diseases and Metabolites. J. Chelkowski and A. Visconti, eds. Elsevier Science Publishers, Amsterdam, The Netherlands.

25. Stierle, A. C., Cardellina, J. H., II, and Strobel, G. A. 1988. Maculosin, a host-specific phytotoxin for spotted knapweed from Alternaria alternata. Proc. Natl. Acad. Sci. USA 85:8008-8011.

26. Tietjen, K. G., Schaller, E., and Matern, U. 1983. Phytotoxins from Alternaria carthami Chowdhury: Structural identification and physiological significance. Physiol. Plant Pathol. 23:387-400.

27. Walton, J. D., and Panaccione, D. G. 1993. Host-selective toxins: Perspectives and progress. Annu. Rev. Phytopathol. 31:275-303. 